\title{
Long-range anomalous electromagnetic effect related to M9 Great Tohoku earthquake
}

\author{
Dragos Armand Stanica, Dumitru Stanica, Nicoleta Vladimirescu \\ Department of Electromagnetism and Lithosphere Dynamics, Institute of Geodynamics of the Romanian Academy, Bucharest, Romania
}

Email address:

armand@geodin.ro (D. A. Stanica), dstanica@geodin.ro (D. Stanica)

To cite this article:

Dragos Armand Stanica, Dumitru Stanica, Nicoleta Vladimirescu. Long-Range Anomalous Electromagnetic Effect Related to M9 Great Tohoku Earthquake. Earth Sciences. Vol. 4, No. 1, 2015, pp. 31-38. doi: 10.11648/j.earth.20150401.13

\begin{abstract}
It is supposed that prior to a large earthquake its focus may send through the Earth lithosphere a long-range effect of strain-related to transient electric signals, which in turn give rise to geomagnetic variations propagated over a wide range of frequencies. Consequently, to confirm long-range electromagnetic anomalous effect related to the M9 Great Tohoku earthquake occurred on 11 March 2011, we retrospectively analyzed the geomagnetic data collected at three observatories placed in Japan (Memambetsu, Kakioka) and Romania (Provita de Sus). The daily mean distributions of the normalized function Bzn and its standard deviation (STDEV) for all the three observatories are performed in the ultra-low frequency range $(0.001-0.016 \mathrm{~Hz})$ by using the FFT band-pass filter analysis. Additionally, a comparative statistical analysis, based on a standardized random variable equation, was applied to the Bzn time series to emphasize a possible pre-seismic anomalous interval and, consequently, a peak greater than 2.5.STDEV, related to the M9 Tohoku earthquake, was identified on 5-6 February 2011. The lead time was 32 days before the earthquake occurrence. The final conclusion is that the detection area of the pre-seismic electromagnetic effect could be extended to the considerable distances from the epicenter of a giant earthquake.
\end{abstract}

Keywords: Pre-Seismic Anomalous Bzn, Crustal Electrical Conductivity Changes, M9 Tohoku Earthquake

\section{Introduction}

On the basis of the last 20 years of the terrestrial, satellite and laboratory studies related to earthquakes preparation in the Earth's lithosphere, one can conclude that at least two possible pre-seismic signatures may occur: (i) direct EM signals of different frequencies generated from the earthquake foci $[2,5,8,9,10,11,12,17,18]$ and (ii) the changes of electric conductivity that, in the conditions imposed by real geophysical properties, may generate internal current concentrations flowing either through the fluid or through the surrounding rocks, which give rise anomalous vertical magnetic fields $[6,7,14,18,21,22$, 24].

In this paper, in order to emphasize the long-range effect of strain-related precursors, we will consider both the approach $\mathrm{R}^{*}[\mathrm{~km}]=10^{0.5 \mathrm{M}-0.27}$ (where $\mathrm{R}^{*}$ is the epicentral distance and $M$ is the earthquake magnitude) as stipulated in [15] and, a comparative statistical analysis applied to the Bzn time series obtained at the three observation sites (Memambetsu, Kakioka and Provita de Sus).

\section{Geotectonic Setting and Seismicity}

On 11 March 2011, a giant earthquake of M9 struck the Japan and both the Japan Meteorological Agency (JMA) and US Geological Survey (USGS) placed the hypocentre of the main shock near the northeast coast of Honshu, at the geographic coordinates $38.322^{\circ} \mathrm{N}, 142.369^{\circ} \mathrm{E}$ and about 24.4 $\mathrm{km}$ depth, as illustrated in Fig. 1. The earthquake was the result of thrust plate faulting on/or near the subduction zone boundary between the Pacific and North America plates. In the epicentral area, the Pacific plate moves approximately westwards with respect to the North America plate with a rate of $83 \mathrm{~mm} / \mathrm{yr}$, and begins its westward descent beneath Japan, at the Japan Trench. The rupture nucleation of the largest events in the Tohoku sequence, including the main shock, was controlled by structural heterogeneities in the mega thrust zone [26]. This earthquake has been preceded by a series of large foreshocks over the previous two days, beginning on 9 March with a seismic event of M7.2 at about $40 \mathrm{~km}$ far, continuing with three earthquakes greater than $\mathrm{M} 7.0$, on 11 March, 2011. Since 1973, the subduction zone of the Pacific Plate under North America Plate, delineated by the Japan 
Trench, hosted nine events of magnitude around 7, two of them being very larges. On 6 June 1978 an earthquake of M 7.7, placed at $35 \mathrm{~km}$ to the southwest of the 11 March epicentre at about $58 \mathrm{~km}$ depth, caused 22 fatalities and over 400 injuries. The other one of M 7.8, located approximately $260 \mathrm{~km}$ to the north of the 11 March epicentre at about $29 \mathrm{~km}$ depth, caused 3 fatalities and almost 700 injuries in December 1994.

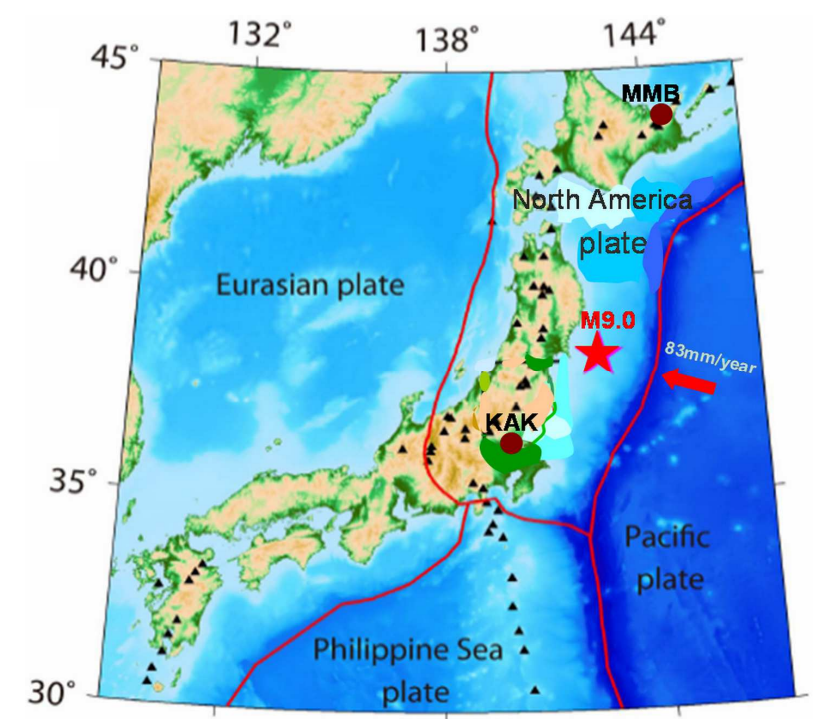

Figure 1. The locations of the $M M B$ and $K A K$ observatories on the geotectonic map (modified after Tong et al. 2012); red star is $M 9$ earthquake; red lines show the major plate boundaries; red arrow indicates the motion of the Pacific Plate relative to the North America Plate.

\section{Basic Theoretical Concepts, Data Collection and Analysis}

\subsection{The Normalized Function Bzn and Its Time Invariance Assumption}

The idea to use the geomagnetic time series to study earthquakes precursors was based on the fact that at the Earth surface the vertical geomagnetic component $(\mathrm{Bz})$ is entirely a secondary field and its existence is an immediate indicator of lateral inhomogeneity. Additionally, for a two-dimensional (2-D) structure, the vertical component $\mathrm{Bz}$ is produced mainly by the horizontal geomagnetic component perpendicular to the geoelectric strike $\left(\mathrm{B}_{\perp}\right)$ and, consequently, a normalized function Bzn is defined as follows:

$$
\mathrm{Bzn}(\mathrm{f})=\mathrm{Bz}(\mathrm{f}) / \mathrm{B}_{\perp}
$$

where (f) is frequency [Hz]. This normalized function should be time invariant in non geodynamic conditions, but it becomes unstable due to the geodynamic processes, so that it could be used as a pre-seismic ULF geomagnetic signature [21, 22].

In order to emphasize the cause (earthquake)-effect (pre-seismic anomalous Bzn) relationship, in [22] is shown that (1) may be rewritten as follows:

$$
|\operatorname{Bzn}(f)|=[\rho \|(f) / \rho z(f)]^{1 / 2}
$$

where $\rho \|$ and $\rho z$ are parallel and vertical resistivities $[\Omega \mathrm{m}]$. As it can be seen in (2), the normalized function Bzn could be linked to the variation of resistivity in the crust, and its right part leads to the normalized resistivity ( $\rho n)$, defined by:

$$
\rho n(f)=\rho \|(f) / \rho z(f)
$$

Consequently, the existence of a 2-D structure gives rise to normalized function Bzn that has a magnitude proportional to the intensity of the anomalous electric current concentrations, which are in turn determined by the resistivity gradient generated in pre-seismic conditions.

\subsection{Geomagnetic Data Collection and Analysis}

The geomagnetic data collected at the Memambetsu (MMB), Kakioka (KAK) and Provita de Sus (PS) observatories during the interval December 2010-March 2011, have been used to identify the pre-seismic ULF geomagnetic signatures related to the M9.0 earthquake. The sampling rate of the three geomagnetic components ( $\mathrm{Bx}$ orientated to the north, By orientated to the east and Bz downwards) was $60 \mathrm{~s}$.

The MMB, KAK and PS observatories have the geographic

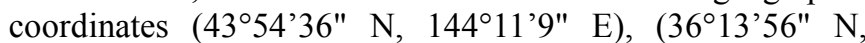

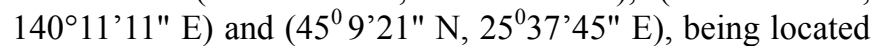
towards north-east, south-west and far north-west, respectively, of the M9.0 earthquake epicentre, as shown in Fig.2, and the criteria of selection are:

(i) Possibility to obtain geomagnetic data at MMB and KAK via internet (www.intermagnet.org) and in real-time for the PS;

(ii) Long-range effect of strain-related to the pre-seismic geomagnetic signature obtained by using the approach $\mathrm{R}^{*}[\mathrm{~km}]=10^{0.5 \mathrm{M}-0.27}$, as in [15], where $\mathrm{R}^{*}$ is the epicentral distance and $\mathrm{M}$ is the earthquake magnitude (in our case $\mathrm{M}=9$ and $\mathrm{R}^{*} \approx 17,000 \mathrm{~km}$ );

(iii) Possibility to investigate the dimensionality characteristics of the geoelectric structure under the measuring sites (MMB, KAK and PS) and to identify the frequency range for which (1) is valid.

For the PS observatory, the dimensionality characteristics of the geoelectric structure were investigated by using single-site magnetotelluric tensor impedance decomposition [1] and, applying the MAPROS software packages [22], it was shown that in the frequency range $0.001-0.0166 \mathrm{~Hz}$ the skewness values are less than 0.3 , what means that the geoelectric structure is of 2-D type, having a strike orientation of about $\mathrm{N} 96^{0} \mathrm{E}$. Thus, to satisfy (1), at the PS observatory one of the horizontal geomagnetic components is always orientated perpendicular to the geoelectric strike of the Carpathian Electrical Conductivity Anomaly (CECA), which on the Romanian territory is delineated by the divergence zone of the induction arrows, Wiese convention [19].

The CECA is generated by the lithospheric faults system that forms in its southern sector a tectonic boundary between the Moesian and Intra-Alpine continental plates.

At global scale, the PS observatory is placed on the EURASIA plate, as it is shown in Fig. 2, nearby the 
Trans-European Suture Zone (TESZ) that separates East-European Precambrian Platform by West-European Palaeozoic Platform [20].

In this paper, we used the existing geomagnetic components $\mathrm{B}_{\perp,}$, and $\mathrm{Bz}$ obtained at PS observatory by a continuous monitoring system (MAG03-DAM, with 6 channel, 24 bit resolution). The parameters of the data acquisition card are under software control that collects information at each five seconds and stored them at every 60 seconds. By means of the wireless connection system, the geomagnetic data are transferred to the central unit, placed at the Institute of Geodynamics-Bucharest, for real-time processing and Bzn time series analysis, mainly, related to the seismic active Vrancea zone.

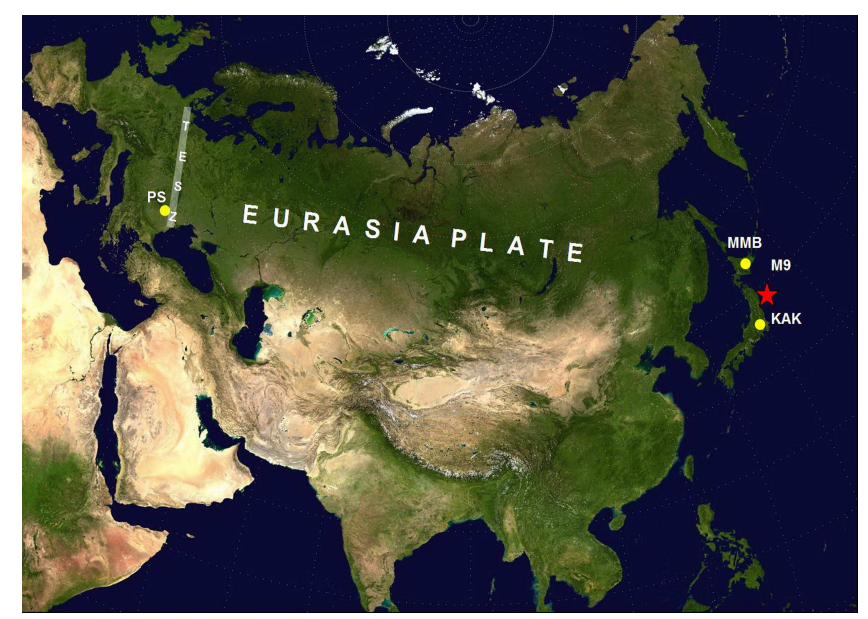

Figure 2. The locations of the $M M B, K A K$ and PS observatories on the EURASIA map; red star is the M9 earthquake; TESZ is the Trans-European Suture Zone.

As regards $\mathrm{MMB}$ and $\mathrm{KAK}$ observatories, due to the fact that for each site we have only three geomagnetic components $(\mathrm{Bx}$, By and $\mathrm{Bz}$ ), that were obtained via internet (link www.intermagnet.org), it was necessary to consider the induction arrows which graphically represent the transfer function between the vertical and horizontal geomagnetic field components. As the vertical magnetic fields are generated by lateral conductivity gradients, induction arrows can be used to infer the presence of lateral variation of the electrical conductivity, so that they are widely used for studying the dimensionality characteristics of the geoelectric structure [3, 19]. The induction arrows are known also as tipper vectors because they transform or tip the horizontal magnetic field into vertical plane according to the relationship:

$$
\mathrm{Bz}(\mathrm{f})=\mathrm{Tx}(\mathrm{f}) \mathrm{Bx}(\mathrm{f})+\mathrm{Ty}(\mathrm{f}) \mathrm{By}(\mathrm{f})
$$

where Tx and Ty are the complex components of the induction arrow.

In a 2-D geoelectric structure, the induction arrows are associated only with the E-polarization mode (sometimes in magnetotellurics referred to as the transverse electric, or TE mode) that describes electrical currents flowing parallel to strike. As a result, resistive-conductor boundaries extended through a 2-D structure give rise to induction vectors that are orientated perpendicular to them.

For the MMB and KAK observatories, in order to select the frequency range where (1) is valid (i.e., existence of a 2-D geoelectric structure and its strike orientation), we applied on the existing geomagnetic data, acquired in the interval December 2010-March 2011, the MAPROS software (multi-windows robust estimation) to obtain the length of the real part of the induction arrows with relation:

$$
\mathrm{T}_{\text {real length }}=|\operatorname{Re}(\mathrm{Tx})|+|\operatorname{Re}(\mathrm{Ty})|
$$

With their orientation:

$$
\mathrm{T}_{\text {real angle }}=\arctan [\operatorname{Re}(\mathrm{Ty}) / \operatorname{Re}(\mathrm{Tx})]
$$

Thus, in the frequency range 0.001-0.0166 Hz, the following data are obtained: (i) for MMB observatory the $\mathrm{T}_{\text {length }} \approx 0.35 ; \mathrm{T}_{\text {angle }} \approx 29^{0}$ (from north over east), and the strike orientation is $\mathrm{N} 119^{0} \mathrm{E}$; (ii) for KAK observatory the $\mathrm{T}_{\text {length }} \approx$ $0.58 ; \mathrm{T}_{\text {angle }} \approx 20^{\circ}$ (from north over west) and the strike orientation is $\mathrm{N} 70^{\circ} \mathrm{E}$

To obtain the geomagnetic component perpendicular $(\mathrm{B} \perp)$ to the 2-D geoelectric strike, we rotated the existing horizontal north component $(\mathrm{Bx})$ with the angle $\alpha=29^{\circ}$ towards east for MMB observatory and, with the angle $\alpha=20^{\circ}$ towards west for KAK observatory, respectively. An example of the new geomagnetic time series $\mathrm{B}_{\perp}$ and $\mathrm{Bz}$, recorded at the $\mathrm{MMB}$ for 5 days (8 February - 12 February 2011), is illustrated in Fig. 3.

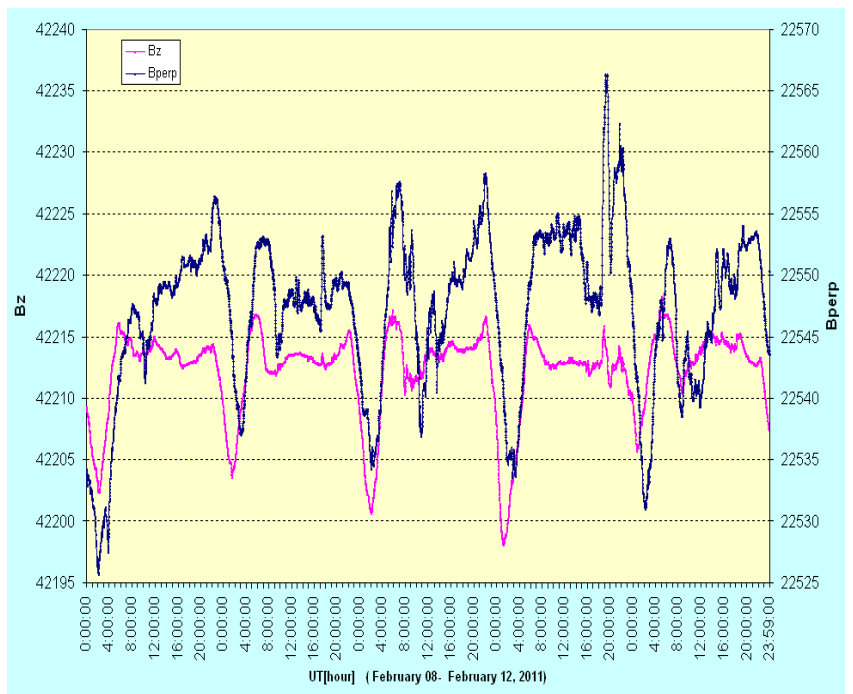

Figure 3. The geomagnetic time series of $B z$ and Bperp $(B \perp)$ on the interval 8 February-12 February 2011.

These new geomagnetic time series, obtained at the KAK, MMB and PS observation sites on the interval December 2010-March 2011, were used to calculate the daily averaged values of the normalized function Bzn and its standard deviation (STDEV) and, consequently, a FFT band-pass filter analysis on the frequency range $0.001-0.0166 \mathrm{~Hz}$, as it is shown in Fig. 4, has been performed for two successive time windows of 1024 samples, with $60 \%$ overlapping on the entire time series of 1440 data points acquired each day. 


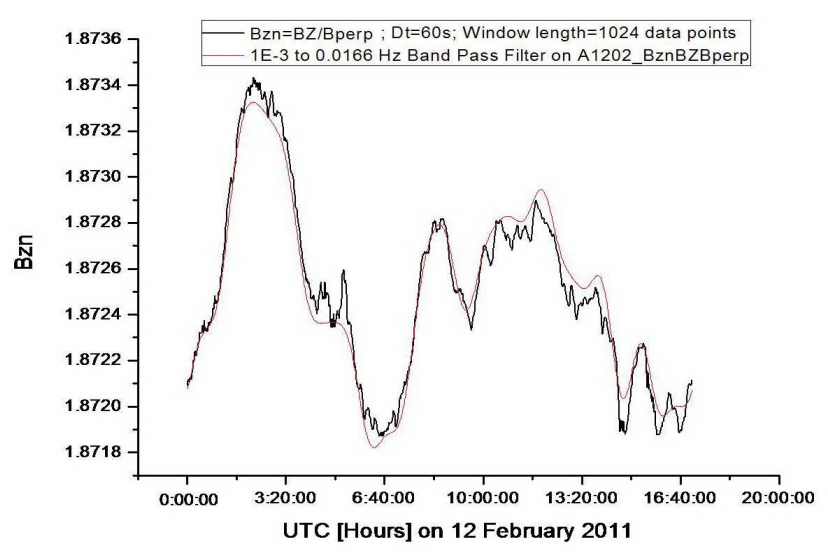

Figure 4. The FFT band-pass filter analysis on the time windows of 1024 samples recorded on 12 February; black line is original Bzn time series; pink line is Bzn distribution in the frequency range $0.001 \mathrm{~Hz}-0.0166 \mathrm{~Hz}$.

\section{Results}

In this study, it was considered that in pre-seismic conditions, the normalized function Bzn has an anomalous behaviour due to the electrical conductivity changes, possibly associated with the earthquake-induced rupture process and fluid flow through the high conductive paths (faults system) extended through the Earth's crust.

In Figs. 5, 6 and 7 we will emphasize how the pre-seismic crustal electrical conductivity changes are reflected by the daily averaged distributions of the normalized function Bzn, carried out at the MMB, KAK and PS observatories during the interval December 2010-March 2011.

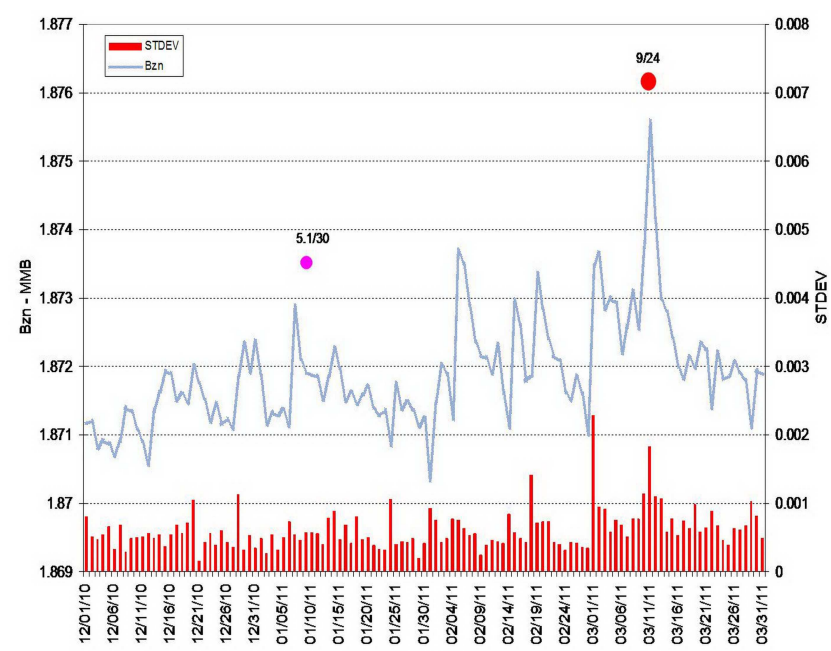

Figure 5. Daily mean distribution of the normalized function Bzn and its STDEV obtained at the MMB observatory during the interval 1 December 2010-31 March 2011; red full circle indicates M9 earthquake; pink full circle is the earthquake of M5.1 occurred near the MMB observatory with $E D \leq R^{*}$ (Table 1); ratio 9.0/24 is the magnitude/hypocenter in $\mathrm{km}$.

Thus, the daily mean distribution of Bzn at the MMB observatory, illustrated in Fig. 5, suggests the presence of two distinct anomalous domains that underlie the seismic activity in the Hokkaido area, including the M9 Tohoku earthquake, as it is summarized in Table 1. The Bzn value of about 1.873 on
January 7, observed on the first domain (1December 2010-4February 2011), is a pre-seismic anomaly associated, the most probably, with an earthquake of M5.1 occurred on 9 January in the Hokkaido area, at $30 \mathrm{~km}$ depth, with an epicentral distances of about $180 \mathrm{~km}$. The second anomalous domain (5 February-11 March 2011), with values of Bzn between 1.873 and 1.875, indicates the possible pre-seismic candidates related to M9 earthquake and the highest value on 11 March is considered to be a co-seismic effect. The last interval (12 March-31 March 2011), with Bzn magnitude of about 1.872, reflects a specific distribution of Bzn after the Tohoku main-shock.

Similar information is reflected by the Bzn distribution at the KAK observatory, as it shown in Fig. 6, where two distinct anomalous domains related to the seismic events, summarized in Table 1, are also identified. So that, on the interval 1 December 2010 - 4 February 2011, the normalized function Bzn has anomalous values between 1.360 and 1.361 that are mainly associated with the two earthquakes of M4.7 and M5.1. The second anomalous interval of Bzn, with values higher than 1.361, extended between 5 February - 11March 2011, emphasizes some possible pre-seismic candidates to the M5.2, M5.4, M4.8, M5.2 and M9 earthquakes, when a co-seismic effect having a maximum value is identified on 11March, as well. The Bzn distribution after M9 earthquake is almost constant, with Bzn variations around the value of 1.3605 .

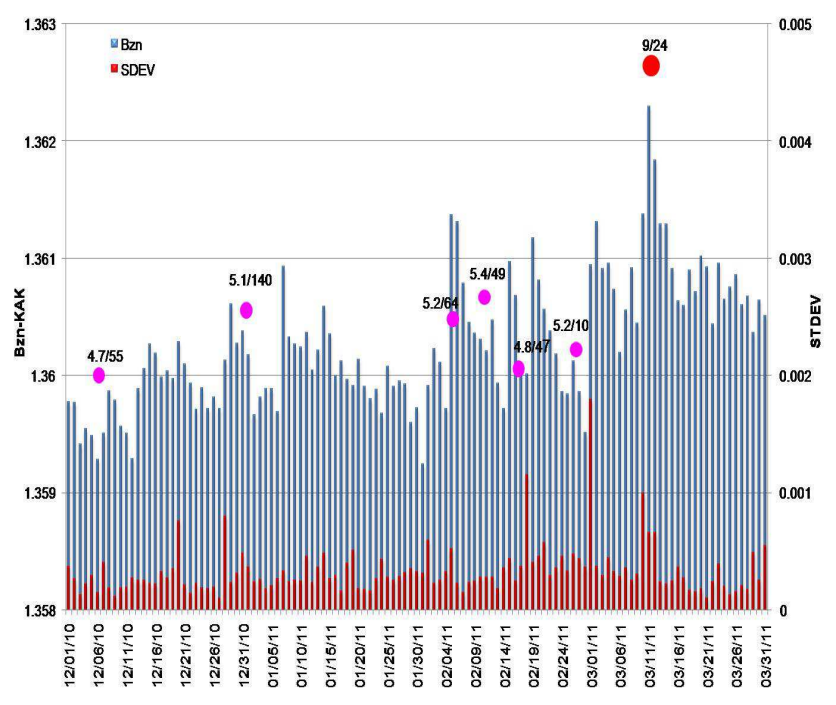

Figure 6. Daily mean distribution of the normalized function Bzn and its STDEV obtained at the KAK observatory during the interval 1December 2010-31March 2011; red full circle indicates $M 9$ earthquake; pink full circles are the earthquakes that occurred near the KAK observatory with $E D \leq R^{*}$, as in Table 1; ratio 9.0/24 is the magnitude/hypocenter in $\mathrm{km}$.

As regards PS observatory, the Fig. 7 depicts unusual anomalous behavior of Bzn, with values ranging from 1.856 to 1.872 , that was obtained on the same interval (1 December 2010-31March 2011). As increased values of Bzn are not justified by the local seismicity occurred in the Vrancea Zone, we have considered that these are, the most probably, a long-range geomagnetic effect related to the M9 Tohoku earthquake, for which a high co-seismic effect on 11 March 
2011 was identified, too. The existence of such effect is consistent with the idea that, in pre-M9 earthquake conditions, the crustal rocks of the EURASIA Platform begin to crack under the action of the very strong stress which leads to the release of electric charges [7]. These charges, carried by the high pressure-fluid flow through the faults system, may generate currents of high amperage which in turn induced disturbances of the geomagnetic field observed at PS observatory.

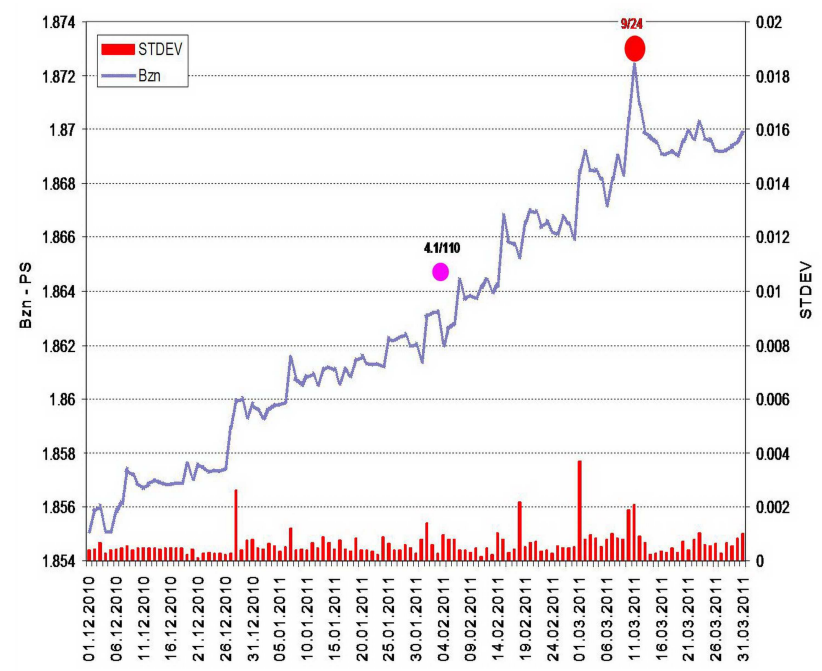

Figure 7. Daily mean distribution of the normalized function Bzn and its STDEV obtained at PS observatory during the interval 1 December 2010-31 March 2011; red full circle indicates M9 earthquake; pink full circle is the earthquake of M4.1 occurred near the PS observatory; ratio 9.0/24 is the magnitude/hypocenter in $\mathrm{km}$.

Although the KAK site is relatively closer to the epicentral location of the Tohoku main-shock (about $370 \mathrm{~km}$ ), the amplitudes of the anomalous pick levels of Bzn, shown in Fig. 6, are less than the amplitude values of the Bzn at the MMB observatory, illustrated in Fig. 5, which is located at a greater distance (about $700 \mathrm{~km}$ ). This information confirms the possibility to associate the pre-seismic anomalous behaviour of Bzn with the resistivity changes due to the fluid flow along the faults system extended parallel with the Japan Trench. The above mentioned idea is in agreement with the seismic hazard map which emphasizes a pick ground acceleration (PGA) at MMB higher than that at KAK $\left(\mathrm{PGA} \mathrm{MMB}=4.8 \mathrm{~m} / \mathrm{s}^{2} ;\right.$ PGA KAK $\left.=3.2 \mathrm{~m} / \mathrm{s}^{2}\right)$, as in (fttp:/hazards.cr.usgs.gov/maps/sigeqs/20110407/20110407.jpg).

To investigate the singularity of the pre-seismic anomalous interval related to the M9 Tohoku earthquake and to eliminate the earthquakes effects manifested around the KAK observatory, as shown in Table 1, the following standardized random variable equation was performed:

$$
\mathrm{Bzn}^{*}=(\mathrm{X}-\mathrm{W}) / \mathrm{Y}
$$

where:

- $\mathrm{X}$ is the value of (Bzn MMB - Bzn KAK) for a particular day, starting with 1 January 2011 and ending on 31 March 2011;

- $\mathrm{W}$ is 30 days running average of (Bzn MMB - Bzn KAK) before the particular day;
- $\mathrm{Y}$ is 30 days running average of (STDEV MMB STDEV KAK) before the particular day;

- Bzn* emphasizes the pre-seismic anomalous interval and represents the threshold for anomaly using STDEV.

After investigating the Bzn* distribution on the interval 01 January-31March 2011, which was obtained by using (7), only two peaks of average magnitude higher than 2.5.STDEV have been identified as possible precursors related to the M9 earthquake, as it is shown in Fig. 8:

- $\quad$ the first one, on the interval 5-6 February 2011, with average value of $\mathrm{Bzn}^{*}=2.7 \cdot \mathrm{STDEV}$;

- $\quad$ the second, on the interval 1-2 March 2011, with average value of Bzn* $=2.9 \cdot \mathrm{STDEV}$.

As it can be seen in Table 1, on 5-6 February when the first pre-seismic anomaly was observed, the geomagnetic activity was quiet $\left(\sum \mathrm{Kp}\right.$ index $\left.=20\right)$, while for the second one, on 1-2 March, an enhancement of the $\mathrm{Kp}$ index $\left(\sum \mathrm{Kp}\right.$ index $\left.=30\right)$ is associated with a geomagnetic storm (www.swpc.noaa.gov/products/planetary-k-index). Thus, only the first pre-seismic anomalous interval identified on 5-6 February is associated, the most probably, with M9 Tohoku earthquake.

Complementarily, we used (7) to investigate the singularity of the pre-seismic anomalous intervals of Bzn obtained at PS observatory, as follows:

- $\mathrm{X}$ is the value of Bzn for a particular day, starting with 01 January 2011 and ending on 31 March 2011;

- $\mathrm{W}$ is 30 days running average of Bzn before the particular day;

- $\mathrm{Y}$ is 30 days running average of STDEV before the particular day;

- Bzn ${ }^{*}$ emphasizes the pre-seismic anomalous interval and represents the threshold for anomaly using STDEV.

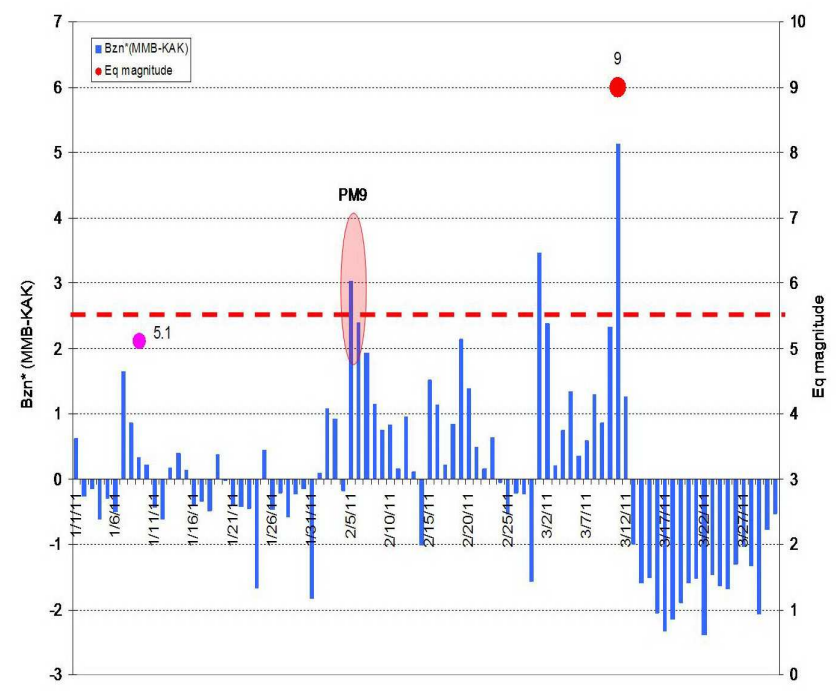

Figure 8. Bzn*(MMB-KAK) time series obtained by using (7); red full circle is M9 Tohoku earthquake; red ellipse (PM9) emphasizes a possible preseismic geomagnetic signature related to M9 Tohoku earthquake; pink full circle is the earthquake of M5.1 occurred near the MMB observatory with $E D \leq R^{*}$, as in Table 1; red dashed line is a threshold for anomaly using the STDEV $\left(B z n^{*}=2.5 \cdot S T D E V\right)$ 
Fig. 9 illustrates the Bzn* time series obtained at PS observatory where some peaks have been identified as possible precursors related to both the local seismicity in Vrancea zone (Romania) and M9 Tohoku earthquake. So, the first peak on 7 January, 2011 may be associated with M4.1 Vrancea earthquake from 3 February 2011. The last two peaks observed on 1-2 March and 11 March 2011 could be generated by the geomagnetic storms $\sum \mathrm{Kp}$ index $=30$ and $\sum \mathrm{Kp}$ index $=34$, respectively, as it is shown in Table 1 . The negative peak of Bzn* time series identified in Fig. 9, on 5-6 February 2011, has a main role in defining the precursor related to M9 Tohoku earthquake, because it is in conformity with the last experimental results obtained in [4], where the authors have investigated the charge generation as a function of stress in the fine-grained gabbro samples using similar conditions that could exist in the active faults zones. In this case, the negative peak observed on 5-6 February in Bzn* distribution, carried out at PS observatory that is placed at the western limit of the EURASIA Plate, is the most probably the pre-seismic electromagnetic effect generated by the M9 earthquake at eastward limit of the EURASIA Plate, as in Fig. 2.

Taking into account that the magnitude of $\mathrm{Bzn}^{*}$ on 11 March is very high it is also consistent with the co-seismic charge generation mechanism due to electrokinetic and triboelectric effect related to the dynamic rupture process due to the M9 Tohoku earthquake [4].

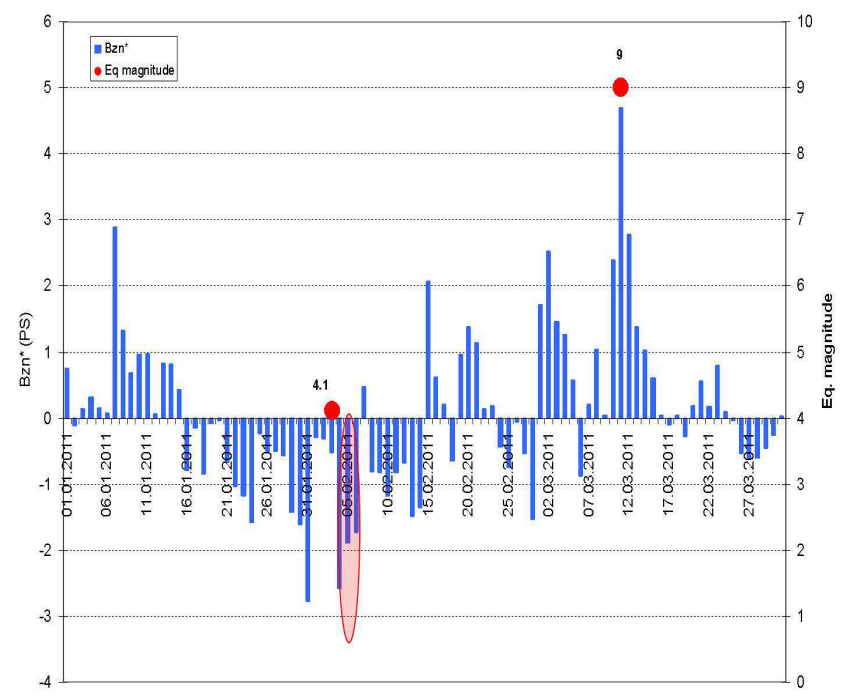

Figure 9. Bzn* time series obtained by using (7); red full circles are M9 Tohoku and M4.1 earthquakes, the last one occurred near the PS observatory; red ellipse emphasizes a possible precursor (as negative peak) related to M9 Tohoku earthquake.

Table 1. The earthquakes occurrence in Japan and their pre-seismic geomagnetic signature illustrated in Fig.5 and Fig.6.

\begin{tabular}{|c|c|c|c|c|c|c|c|c|c|}
\hline \multicolumn{4}{|c|}{ Earthquakes with $M \geq 4.8$ (after EMSC) } & \multirow{2}{*}{$\begin{array}{l}\text { JAPAN Region } \\
\text { (near MMB) }\end{array}$} & \multicolumn{5}{|c|}{ Pre-seismic geomagnetic signature } \\
\hline Date & $\mathbf{M}$ & Depth km & ED km & & Date & Bzn value & Lead time days & $\mathbf{R} * \mathbf{k m}$ & $\sum \mathbf{K p}$ \\
\hline 2011-03-11 & 9.0 & 24 & 700 & Tohoku & $\begin{array}{l}2011-03-11 \\
2011-03-5,6\end{array}$ & $\begin{array}{l}1.8755 \\
1.8736\end{array}$ & $\begin{array}{l}\text { co-seismic } \\
32\end{array}$ & 16,980 & $\begin{array}{l}34 \\
20\end{array}$ \\
\hline 2011-01-22 & 5.0 & 60 & 210 & Hokkaido & - & - & - & 170 & \\
\hline 2011-01-09 & 5.1 & 30 & 180 & Hokkaido & 2011-01-07 & 1.8728 & 2 & 190 & 18 \\
\hline $2010-12-15$ & 5.2 & 47 & 350 & Hokkaido & - & - & - & 210 & \\
\hline $2010-12-01$ & 4.8 & 40 & 270 & Hokkaido & - & - & - & 135 & \\
\hline Date & M & Depth km & ED km & (near KAK) & Date & Bzn value & Lead time days & $\mathrm{R}^{*} \mathrm{~km}$ & $\sum \mathrm{Kp}$ \\
\hline 2011-03-11 & 9.0 & 24 & 375 & Tohoku & $\begin{array}{l}2011-03-11 \\
2011-02-5,6\end{array}$ & $\begin{array}{l}1.3623 \\
1.3613\end{array}$ & $\begin{array}{l}\text { co-seismic } \\
32\end{array}$ & 16,980 & $\begin{array}{l}34 \\
20\end{array}$ \\
\hline $2011-02-26$ & 5.2 & 10 & 180 & E. Honshu & 2011-02-19 & 1.3611 & 6 & 210 & 7 \\
\hline $2011-02-25$ & 4.9 & 60 & 175 & E. Honshu & - & - & - & 150 & - \\
\hline $2011-02-17$ & 4.8 & 47 & 135 & E. Honshu & $2011-02-15$ & 1.3609 & 2 & 135 & 10 \\
\hline 2011-02-10 & 5.4 & 49 & 240 & E. Honshu & 2011-02-06 & 1.3613 & 4 & 270 & 20 \\
\hline 2011-01-16 & 4.8 & 40 & 240 & E. Honshu & - & & & 135 & \\
\hline $2011-01-03$ & 4.8 & 40 & 280 & E. Honshu & - & & & 135 & \\
\hline 2011-01-02 & 4.6 & 50 & 200 & E. Honshu & - & & & 110 & \\
\hline $2010-12-31$ & 5.1 & 54 & 140 & E. Honshu & $2010-12-29$ & 1.3606 & 2 & 190 & 6 \\
\hline $2010-12-05$ & 4.7 & 55 & 70 & E. Honshu & $2010-12-02$ & 1.3597 & 3 & 120 & 12 \\
\hline
\end{tabular}

EMSC - European Mediterranean Seismological Centre; $M$ - earthquake magnitude; ED - epicentral distance related to MMB and KAK; ${ }^{*}$ - epicentral distance at which the pre-seismic effect is felt, according to [15]; the dark grey rows emphasise the earthquakes with $E D \leq \mathrm{R}^{*}$.

\section{Conclusions}

The geomagnetic data collected at the three observatories placed in Japan (Memambetsu, Kakioka) and Romania (Provita de Sus) have been retrospectively analyzed on the interval December 2010 - March 2011 to emphasize possible pre-seismic geomagnetic signatures related to the M.9 great Tohoku earthquake.

The proposed geomagnetic methodology regarding the distribution of the normalized function Bzn and its anomalous intervals examination, on the base of the standardized random variable equation, provided adequate information to identify on 5-6 February 2011 a possible pre-seismic peak level higher than 2.5.STDEV. The negative peak identified on the same interval in the Bzn* time series, carried out at the PS observatory, is the most probably the effect of the M9 Tohoku earthquake [4]. The lead time is 32 days and it appears to be in agreement with the other statistical results carried out for the land earthquakes in Japan [13]. 
Taking into account the results obtained for VLF/LF lower ionosphere perturbations [12] and infrared radiation [17], identified on 5-6 March 2011 and 7-8 March, respectively, it is highly recommended to combine more methodologies to investigate both the mid-term (about one month) and short-term (days) precursors related to earthquakes. This seems to suggest that the pre-seismic electromagnetic signals, spanning a wide frequency range (MHz, VLF/LF and ULF), arise from the consecutive stages of the M9 earthquake preparation processes.

Finally, we conclude that the long-range anomalous electromagnetic effect is consistent with the idea that its occurrence at the PS observatory is due to the earthquake-induced faulting processes, associated with high pressure-fluid flow and electrical conductivity variation through the crustal rocks of the Trans-European Suture Zone (TESZ) and CECA, both placed at the western limit of the EURASIA Plate.

\section{Acknowledgements}

The results presented in this paper rely on data collected at three observatories placed in Japan (Memambetsu and Kakioka) and Romania (Provita de Sus). We thank the national institutes that support them and INTERMAGNET for promoting high standards of magnetic observatory practice (www.intermagnet.org). This paper was presented at EGU General Assembly 2014, with the financial support of the ANCS-UNEFISCDI, PN II - IDEI, project number 93/2011.

\section{Nomenclature}

$\mathrm{Bx}, \mathrm{By}, \mathrm{Bz}=$ Components of geomagnetic field (geomagnetic induction) in Cartesian co-ordinates $\left[\mathrm{Tesla}(\mathrm{T})=\mathrm{Vsm}^{-2}\right]$

$\mathrm{B}_{\perp}=$ Component of geomagnetic field perpendicular to geoelectric strike [T]

E-polarization $=$ For a two dimensional (2-D) structure the electric field (Ex) parallel to strike is associated with magnetic field (By) perpendicular to strike

Induction arrows $=$ Vectorial representation of the complex ratios of vertical to horizontal magnetic field components, shown in (4), to emphasize the lateral conductivity variation $\mathrm{Kp}$ index $=$ Estimated 3-hours Planetary index which it used to characterize the magnetic storms

$\sum \mathrm{Kp}$ index $=$ Daily sum of $\mathrm{Kp}$ index

$\mathrm{LF} / \mathrm{VLF} / \mathrm{ULF}=$ Low/very-low/ultra-low frequency [Hz]

Skewness $=$ dimensionality parameter of geoelectric structure Strike $=$ direction of the higher conductivity in a 2-D structure Robust estimation $=$ statistical analysis that utilizes iterative weighting of residuals to identify and eliminate data biased by non-Gaussian noise

\section{References}

[1] Bahr, K. Interpretation of the magnetotelluric impedance tensor: regional induction and local telluric distortion, J. Geophys., 62, 1988, pp. 119-127.
[2] Biagi, P.F.; Maggipinto, T.; Righetti, F.; Loiacono, D.; Schiavulli, L.; Ligonzo, T.; Ermini, A.; Moldovan, I.A.; Moldovan. A.S.; Buyuksarac, A.; Silva, H.G.; Bezzeghoud, M.; Contadakis, M.E. The European VLF/LF radio network to search for earthquake precursors: setting up and natural/man-made disturbances. Nat. Hazards Earth Syst. Sci., 11, 2011, pp. 333-34.

[3] Brasse, H.; Kaoinos, G.; Li, Y.; Mutschard, L.; Soyer, W.; Eydam, D. Structural electrical anisotropy in the crust at the South-Central Chilean continental margin as inferred from geomagnetic transfer functions. Phys. Earth. Planet. Inter., 173, doi: 10.1016/j.pepi. 2008.10.017, 2009, pp.7-16.

[4] Dahlgren, R.P.; Johnston, M.J.S.; Vanderbilt, V.C.; Nakaba, R. N. Stress-stimulated current in dry and fluid saturated gabbro, EMSEV 2014 Workshop, Warsaw, September 2014, Book of Abstracts, pp. 146-147.

[5] Dunson, J.C.; Bleier, T.E.; Roth, S.; Heraud, J.; Alvarez, C.H.; Lira, A. The pulse azimuth effect as seen in induction coil magnetometers located in California and Peru 2007-2010, and its possible association with earthquakes. Nat. Hazards Earth Syst. Sci., 11. doi: 10.5194/nhess- 11-2085, 2011, pp. 2085-2105.

[6] Fenoglio, M.A.; Johnston M.J.S.; Bierlee, J.D. Magnetic and electric fields associated with changes in high pore pressure in fault zones: application to the Loma Prieta ULF emissions. J. Geophys. Res. 100, 1995, pp. 12951-12958.

[7] Freund, F.T. Charge generation and propagation in rocks. J. Geodyn. 33(4-5), 2002, pp.545-572.

[8] Johnston, M.J.S. Review of electric and magnetic fields accompanying seismic and volcanic activity. Surv. Geophys., 18, 1997, pp. 441-475.

[9] Kopytenko, Y.A.; Matiashvili, T.G.; Voronov, P.M.; Kopytenko, E.A. Observation of electromagnetic ultra-low-frequency lithospheric emission in the Caucasian seismically active zone and their connection with earthquakes, In: Electromagnetic Phenomena related to Earthquake Prediction, Hayakawa and Fujinawa, Terra Scientific Pub. Comp. Tokyo, 1994, pp. 175-180.

[10] Hattori, K.; Serita, A.; Yoshino, C.; Hayakawa, M.; Isezaki, N. Singular spectral analysis and principal component analysis for signal discrimination of ULF geomagnetic data associated with 2000 Izu Island earthquake swarm. Phys. Chem. Earth, 31, 2006, pp. 281-291.

[11] Hayakawa, M. and Molchanov, O.A. SeismoElectromagnetics: Lithosphere-Atmosphere-Ionosphere Coupling, Terra Scientific Pub. Comp., Tokyo, 2002.

[12] Hayakawa, M.; Hobara, Y.; Yasuda, Y.; Yamaguchi, H.; Ohta, K.; Izutsu, J.; Nakamura, T. Possible precursor to the March 11, 2011, Japan earthquake: ionospheric perturbations as seen by subionospheric very low frequency/low frequency propagation. Annals of Geophysics 55, 1, doi: 10.4401/ag- 5357, 2012, pp. 95-99.

[13] Hirano, T. and Hattori, K. ULF geomagnetic changes possibly associated with the 2008 Iwate-Miyagi Nairiku earthquake, Elsevier, Journal of Asian Earth Sciences 41 (2011), 2011, pp. 442-449.

[14] Mogi, K. Earthquake prediction, Academic Press, Tokio, 1985. 
[15] Morgunov, V.A. and Malzev, S.A. A multiple fracture model of pre-seismic electromagnetic phenomena, Tectonophysics 431, 2007, pp. 61-72.

[16] Ouzounov, D.; Bryant, N.; Logan, T.; Pulinets, S.; Taylor, P. Satellite thermal IR phenomena associated with some of the major earthquakes in 1999-2003, Physics and Chemistry of the Earth, 31, 2006, pp. 154-163.

[17] Ouzounov, O.; Pulinets, S.; Romanov, A.; Tsybulya, K.; Davidenko, D.; Kafatos, M.; Taylor, P. Atmosphere-ionosphere response to the M9 Tohoku earthquake revealed by multi-instrument space-borne and ground observations: Preliminary results. Earthq. Sci. 24, doi: 10.1007/s 11589-011-0817-z, 2011, pp. 557-564.

[18] Park, S.K.; Johnston, M.J.S.; Madden, T.R.; Morgan, F.D.; Morrison, H.F. Electromagnetic precursors to earthquakes in the ULF band - review of observations and mechanisms, Rev. Geophys., 31, 1993, pp. 117-132.

[19] Simpson, F. and Bahr, K. Practical magnetotellurics, Cambridge University Press, 2005.

[20] Stanica, M.; Stanica, D.; Marin-Furnica, C. The placement of the Trans-European Suture Zone on the Romanian territory by electromagnetic arguments, Earth Planets Space, 51, 1999, pp.
1073-1078.

[21] Stanica, D. and Stanica, D.A. Constraints on Correlation Between the Anomalous Behaviour of Electromagnetic Normalized Functions (ENF) and the Intermediate Depth Seismic Events Occurred in Vrancea Zone (Romania), Terr. Atmos. Ocean. Sci., 21, doi:10.3319/TAO.2009. 09.09.01(T), 2010, pp. 675-683.

[22] Stanica, D. and Stanica, D. A. Anomalous pre-seismic behaviour of the electromagnetic normalized functions related to the intermediate depth earthquakes occurred in Vrancea zone, Romania, Nat. Hazards Earth Syst. Sci., 11, doi: 10.5194/nhess-11-3151, 2011, pp. 3151-3156.

[23] Tong, P., Zhao, D. and Yang, D. Tomography of the 2011 Iwaki earthquake (M7.0) and Fukushima nuclear power plant area. Solid Earth, 3, doi: 10.5194/se-3-43-2012, pp. 43-51.

[24] Varotsos, P. The Physics of Seismic Electric Signals, TERRAPUB, Tokyo, 2005.

[25] Zhao, D.; Huang, Z.; Umino, N.; Hasegawa, A; Kanamori, H. Structural heterogeneity in the mega-thrust zone and mechanism of the 2011 Tohoku-oki earthquake (Mw 9.0). Geophys. Res. Lett., 38, L17308, doi: 10.1029/2011GL 048408, 2011, 5pp. 